\title{
RESEÑA: CONSTANCE DE SALM Y LA MODERNIDAD DE SU \\ DISCURSO FEMINISTA. EPÍSTOLAS Y OTROS ESCRITOS (1767- \\ 1845). ÁNGELA MAGDALENA ROMERA PINTOR ${ }^{1}$
}

\author{
Milagro Martín Clavijo²
}

\begin{abstract}
Ángela Magdalena Romera Pintor, Constance de Salm y la modernidad de su discurso feminista. Epístolas y otros escritos (1767-1845). Valencia: PUV, 2015. ISBN: 9788437096469.
\end{abstract}

Constance de Salm, poetisa y moralista que se dio a conocer en la época de la Revolución francesa y que alcanzaría su mayor gloria literaria en tiempos del imperio napoleónico, regentaba su propio salón literario en París y fue la primera mujer en ser admitida en el Liceo de las Artes, en 1795. La que fuera conocida como "ciudadana Pipelet" había gozado en vida de una celebridad que permitía augurar la pervivencia de su legado literario para las futuras generaciones de los siglos venideros:

Su nombre se recogió en las grandes obras enciclopédicas del momento, como $L a$ biografía de los hombres vivos [...], la monumental Biografía universal antigua y moderna [...] de Michaud, o bien aún La Francia literaria [...] de Quérard. También los artículos en revistas y periódicos de la época se ocupan con regularidad de las distintas publicaciones de Constance y abundan noticias biográficas dedicadas a su persona ya en vida de la autora y que proliferarán con renovado interés inmediatamente después de su muerte. (Romera 2015: 259)

A diferencia de Madame de Staël, la postura de Constance de Salm, abiertamente favorable a Napoleón, permitió sin duda "que sus escritos prosperaran sin obstáculos en

\footnotetext{
${ }^{1}$ Fecha de recepción: 01/07/2015.

Fecha de aceptación: 30/07/2015.

${ }^{2}$ Profesora Titular, Departamento de Filología Moderna, Área de Filología Italiana, Universidad de Salamanca; $\bowtie$ mclavijo@usal.es.
} 
la Francia imperial" (Romera 2015: 264). Y sin embargo, a los pocos años de su muerte ${ }^{1}$, el nombre de la princesa de Salm caería en un olvido casi absoluto, y ello a pesar de que había procurado "facilitar la tarea de su supervivencia literaria" (Romera 2015: 255) mediante la compilación de la totalidad de sus obras en dos ocasiones, la primera en 1835 , la segunda y más completa en 1842, así como esforzándose en transcribir su abundante correspondencia con objeto de publicarla ${ }^{2}$.

Tras quedar sepultada en el olvido durante siglo y medio, pocos críticos en nuestros días se han ocupado de esta escritora. Si hasta 2007 apenas algunos estudiosos le habían otorgado una atención ocasional, a partir de ese año, la reedición de la única novela epistolar de Constance de Salm desencadenó en el seno del mundo académico francés una atención renovada hacia esta olvidada mujer de letras. El detonante del interés crítico por su obra serían las Jornadas de estudio celebradas en Toulouse en $2009^{3}$, dedicadas por entero a la que fuera conocida como la “Musa de la razón”. Y es que la reedición de 2007 de Veinticuatro horas en la vida de una mujer sensible 4 obtuvo en Francia un éxito insospechado hasta el punto de que no sólo se reeditaría sucesivamente, sino que también sería traducida de inmediato tanto en Alemania, como en Italia y España. Y así en los últimos años, desde Francia hasta Nueva York, algunas tesis doctorales, entre otras publicaciones, se han venido a ocupar de la princesa de Salm de forma más detenida.

En España, sin embargo, la obra de la princesa de Salm permanecía inexplorada hasta la publicación del libro Constance de Salm y la modernidad de su discurso feminista. Epístolas y otros escritos (1767-1845), de 2015, en el que Ángela Magdalena Romera Pintor estudia el discurso feminista de la princesa, nacida Constance de Théis,

\footnotetext{
${ }^{1}$ Constance de Salm murió el 13 de abril de 1845 en París.

${ }^{2}$ Romera Pintor señala en su libro la existencia de un volumen titulado Quelques lettres extraites de la Correspondance générale de 1805 à 1810, que Constance habría publicado en 1841, pero que no llegaría a salir a la venta, según recoge Michaud en su Biografía universal, de 1843 (Romera 2015: 255).

${ }^{3}$ Fruto de estas Jornadas de estudio, "La Muse de la raison, Constance de Salm (1767-1845): poétesse, moraliste et bas-bleu", fue la publicación de todas las intervenciones en el número 29 de los Cahiers Roucher-André Chénier, número monográfico titulado La muse de la raison: Constance de Salm, 2010.

${ }^{4}$ Vingt-quatre heures d'une femme sensible.
} 
conocida también como ciudadana Pipelet, condesa de Salm y finalmente princesa de Salm ${ }^{5}$.

En la primera parte de su libro, Romera Pintor reconstruye la carrera literaria y la vida de Constance de Salm, su personalidad, las relaciones con su círculo intelectual y con la corte imperial, las circunstancias de la publicación de sus obras, el conjunto de su producción, así como el ambiente histórico, todo ello reconstruido a partir de los escritos de sus contemporáneos, de sus biógrafos, de las publicaciones y comentarios de la propia Constance, de su correspondencia, y de la prensa del momento: "Existen, por tanto, numerosos documentos y referencias de la época que nos permiten trazar la vida y obra de este ilustre personaje femenino, poeta y moralista, cuya juventud se desarrolla durante la Revolución francesa y que alcanzaría su mayor gloria literaria durante el Imperio" (Romera 2015: 17). Romera Pintor explora en su libro las vicisitudes de una mujer segura de su talento y al mismo tiempo atormentada por la ansiedad que le procuraba la recepción de su obra, movida por su amor propio, firme en sus convicciones, que ambicionaba la gloria literaria y que emprendió, con entusiasmo, la defensa de su sexo ${ }^{6}$ en una época en la que el debate sobre los derechos de las mujeres autoras se había reavivado con virulencia.

La primera obra de envergadura de la ciudadana Pipelet fue Sapho, de 1794, tragedia lírica en tres actos y en verso que alcanzó más de cien representaciones y que le procuraría una celebridad inmediata. Por su parte, con la Epístola a las mujeres ${ }^{7}$, uno de los escritos más aplaudidos de Madame Pipelet en el que aborda el derecho de las mujeres a la gloria literaria, alcanzó su mayor éxito en la materia y la consagraría como "Musa de la Razón". Animada por estos triunfos, Constance desarrollará su discurso feminista en buena parte de sus composiciones, incidiendo en la reivindicación de los derechos de la

\footnotetext{
${ }^{5}$ En 1789 Constance de Théis se casa con Jean-Baptiste Pipelet de Leury y firma entonces sus escritos como ciudadana Pipelet. Tras divorciarse de su primer marido, un segundo matrimonio la convertirá en condesa de Salm-Dyck. Más tarde, su segundo esposo obtendrá el título de príncipe del rey de Prusia. Será entonces cuando se la conocerá como princesa de Salm, nombre con el que firmará la segunda edición de sus Obras completas, de 1842.

${ }^{6}$ Se trata de la expresión que utilizaba la propia Constance en sus escritos (Romera 2015: 124): "satisfaite d'avoir plaidé la cause de mon sexe en général" ("satisfecha de haber defendido en general la causa de mi sexo").

${ }^{7}$ Épître aux femmes, 1797.
} 
mujer en el campo de las letras y de las artes frente al dominio masculino. Y lo hará principalmente a través de sus epístolas, por cuanto el fracaso de su tragedia Camille, de 1800, la empujaría a tomar la decisión de abandonar la composición de obras teatrales para dedicarse de lleno al género epistolar, en el que había sabido desplegar su talento y que le había granjeado el aprecio de la crítica y de los lectores. Este tipo de poesía, bien acogida por el público, le pareció por lo mismo más favorable a su ambicionada celebridad literaria que las obras de teatro, según confiesa de forma elocuente la propia Constance en el Avant-Propos de sus Obras completas (Romera 2015: 29): “[...] por cuanto la acogida que el público brindaba a mis epístolas me había decidido a dedicarme a este tipo de poesía, que me pareció más favorable aún para la celebridad que una obra de teatro".

El estudio de la obra de la princesa de Salm se aborda en la segunda parte del libro, donde Romera Pintor analiza el discurso feminista de Constance de Salm no sólo en la Epístola a las mujeres, sino también -entre otras-en las seis Epístolas a Sofía ${ }^{8}$, así como en la Epístola al Emperador Napoleón ${ }^{9}$, donde la escritora refutará enérgicamente los artículos 324 y 339 del código penal, que discriminaban a las mujeres: "La epístola a Napoleón no tuvo consecuencias en el código penal pero obtuvo el reconocimiento por parte del emperador, una pequeña satisfacción que en términos de Constance 'fue la única que me valió mi epístola"” (Romera 2015: 83).

El tema feminista será desarrollado en otros textos poéticos de la princesa (Consejos a las mujeres, Boutade sobre las mujeres autoras y Sobre las mujeres políticas ${ }^{10}$ ), así como en algunos escritos en prosa: en su Informe sobre la condición de las mujeres en una República ${ }^{11}$ Constance aborda los argumentos de un opúsculo de Théremin para apoyar la causa feminista; en su libro inacabado De los alemanes comparados con los franceses $^{12}$, que sólo consta de tres capítulos, la escritora presenta sus observaciones sobre la vida de los matrimonios en Alemania, y en particular sobre las mujeres alemanas,

\footnotetext{
${ }^{8}$ Épîtres à Sophie, 1801.

${ }^{9}$ Épître adressée à l'empereur Napoléon, 1810.

${ }^{10}$ Conseil aux femmes, Boutade sur les femmes auteurs (1798) y Sur les femmes politiques (1817).

${ }^{11}$ Rapport sur un ouvrage intitulé: De la condition des femmes dans une République, 1799.

${ }^{12}$ Des Allemands comparés aux Français, dans leurs mours, leurs usages, leur vie intérieure et sociale, 1826.
} 
comparándolas con sus compatriotas, e incide en su defensa del derecho de la mujer a la educación y a su acceso a la vida literaria; finalmente, en sus Pensamientos ${ }^{13}$, un volumen en tres partes, Constance recoge sus meditaciones sobre numerosos temas a través de reflexiones vitales, incluso de observaciones filosóficas o morales, y condensa en ellas sus reivindicaciones feministas.

Todos estos textos son analizados por Romera Pintor, que estudia tanto las circunstancias de su composición y publicación, como las apreciaciones de toda índole relativas a estas obras que proporcionaron en sus escritos y en la prensa del momento los contemporáneos de la escritora. En su análisis sobre las reivindicaciones feministas defendidas por la princesa de Salm a lo largo de sus obras, Romera Pintor lleva a cabo el estudio comparado entre los razonamientos de Constance en la materia y los de sus contemporáneas, Germaine de Staël y Olympe de Gouges, con objeto de determinar las divergencias y analogías de sus respectivos discursos feministas.

Finalmente, antes del capítulo dedicado a las conclusiones, capítulo rico y denso que analiza los resultados de la investigación, una última parte del libro se ocupa de los textos poéticos, vertidos al español por primera vez, y donde se ofrece la transcripción de las dos versiones en paralelo. En su versión española, Romera Pintor reproduce hábilmente tanto el fondo, el sentido y el contenido del discurso poético de la princesa de Salm, como el estilo, la rima y la forma del original. Y lo que es más meritorio, la cuidada versión española de Romera Pintor consigue rendir la retórica apasionada de Constance, el espíritu y el tono de sus versos, así como su sabor histórico. Por su parte, la concluyente notación que acompaña las dos versiones completa de forma efectiva el estudio analítico del volumen.

En definitiva, el libro Constance de Salm y la modernidad de su discurso feminista. Epístolas y otros escritos (1767-1845) viene a ser una obra de referencia ineludible para todos los investigadores y especialistas de la princesa de Salm, y de indudable interés para todos los estudiosos de la literatura de género y de la literatura feminista. Por lo

\footnotetext{
${ }^{13}$ Pensées, publicado en tres partes: la primera en 1829, la segunda (junto con la primera) en 1835 y la tercera en 1846, edición póstuma que también incluye las dos primeras partes.
} 
demás, los amantes de las letras podrán saborear la lectura de una investigación bien llevada, de un estudio crítico consistente y riguroso, y al mismo tiempo cautivante y de fácil lectura, sobre una mujer de letras de la literatura francesa, apasionada defensora de los derechos de su sexo, rescatada al fin de un olvido casi absoluto.

Otras obras de la princesa de Salm, como sus memorias, Mis sesenta años ${ }^{14}$, y su novela epistolar, Veinticuatro horas en la vida de una mujer sensible $e^{15}$, también han sido analizadas por Romera Pintor en dos artículos publicados respectivamente en la revista Çédille (2015) y en la revista Anales de Filología Francesa (2014), artículos que vienen a completar la investigación llevada a cabo con éxito en este volumen dedicado al estudio del discurso feminista de Constance de Salm.

\footnotetext{
${ }^{14}$ Mes soixante ans, ou mes souvenirs politiques et littéraires, 1833.
}

${ }^{15}$ Vingt-quatre heures d'une femme sensible, 1824. 